\title{
O DESAFIO DAS COOPERATIVAS DE CRÉDITO SOLIDÁRIO NA ZONA DA MATA DE MINAS GERAIS
}

MARTINS, Márcia Eliana. Mestra em Desenvolvimento Rural (UFRGS), Rua São Paulo, 1190/1402, Belo Horizonte/MG. CEP:30170-131. E-mail: me.martins2010@ gmail.com.

FREITAS, Alair Ferreira de. Mestrando em Extensão Rural, Universidade Federal de Viçosa.

E-mail: alairufv@yahoo.com.br.

DIAS, Marcelo Miná. Professor-adjunto do Departamento de Economia Rural, Universidade Federal de Viçosa.E-mail:minad@uol.com.br.

FILIPPI, Eduardo Ernesto. Professor adjunto do Departamento de Ciências Econômicas, Universidade Federal do Rio Grande do Sul. E-mail: edu_292000@yahoo.com.br.

\begin{abstract}
Resumo
Voltadas à inclusão financeira da agricultura familiar, as cooperativas de crédito solidário atuam -além do mero acesso ao crédito - na melhoria da qualidade de vida daqueles com os quais interagem. Tal como os bancos, as cooperativas de crédito enquanto instituições financeiras estão sujeitas aos normativos e regulamentações do Sistema Financeiro Nacional, fato que gera uma série de procedimentos e normas para garantir seu funcionamento. Nesse sentido, este trabalho procura evidenciar, através dos discursos dos associados, o dilema no qual se vê uma dessas cooperativas: de que forma manter uma proposta alternativa aos bancos comerciais, sem descumprir as normas e procedimentos ditados pelo Sistema Financeiro Nacional? De acordo com os dados obtidos nas 32 entrevistas e observação em reuniões de diretoria, durante a realização da pesquisa de mestrado intitulada "O Cooperativismo de Crédito Solidário e as Representações Sociais da Cooperação nos municípios de Araponga e Tombos/MG", por um lado, existe a preocupação em garantir que sejam seguidas as normas do sistema financeiro e que as cooperativas tenham sua gestão mais profissionalizada. Por outro, há uma imensa preocupação em não deixar que essas normas afetem sua forma diferenciada de atuação, em que os agricultores têm acesso aos serviços financeiros de que necessitam. Não há uma saída definitiva, tampouco imediata, para essa questão. Existem apenas apontamentos iniciais que não garantem resultados referentes a todos os aspectos considerados importantes, como a valorização dos laços de confiança em consonância com a atuação de uma instituição financeira em expansão.
\end{abstract}

Palavras-chave: Cooperativismo de crédito; Economia solidária; Sistema Financeiro Nacional.

\begin{abstract}
Aimed at financial inclusion of family farmers, solidary credit cooperatives act - besides mere access to credit - to improve the quality of life of those with whom they interact. Such as banks, credit cooperatives as financial institutions are subject to standards and regulations of the National Financial System, fact that generates a series of procedures and rules in order to guarantee their operation. In this sense, this paper emphasizes, through the speeches of their members, the dilemma in which we see one of these cooperatives: how to keep an alternative proposal to the commercial banks, without disobeying the rules and procedures dictated by the National Financial System? According to the data obtained in the 32 interviews and in the observation of directors' meetings, during the elaboration of the Master research entitled "The Solidary Credit Cooperativism and Social Representations of Cooperation in the cities of Tombos and Araponga/MG", on the one hand, there is a preoccupation with guaranteeing that the financial system's rules are followed and that the cooperatives have more professional management. On the other hand, there is a huge preoccupation with not to allow that these rules affect the differentiated performance form, in which farmers have access to financial services they
\end{abstract}


need. There is not an immediate or definitive solution for this question. There are only some initial notes that do not guarantee results for all the aspects considered important, like the appreciation of the bonds of trust in consonance with the performance of a financial institution in expansion.

Keywords: Credit union; Solidarity Economy; Financial System.

\section{INTRODUÇão}

(...) como as cooperativas de crédito podem atuar junto aos mais pobres, já que eles têm poucos recursos financeiros para movimentar e elas precisam sobreviver no mercado capitalista? (BÚRIGO, 2006: 160)

O cooperativismo de crédito solidário pode ser entendido como um instrumento de democratização do acesso ao crédito àqueles que estão "à margem" dos circuitos financeiros tradicionais. Pauta-se por uma proposta de trabalho diferenciada e, assim, menos burocrática do que a praticada pelos bancos comerciais. No Brasil, esta forma de cooperativa enfrentou - e ainda enfrenta - alguns obstáculos ao seu pleno funcionamento. Um exemplo prático é a adequação aos moldes ditados pelo Sistema Financeiro Nacional-SFN, através das resoluções e normativos baixados pelo Conselho Monetário Nacional-CMN via Banco Central - Bacen ${ }^{1}$.

Nesse sentido, a discussão realizada no presente trabalho gira em torno da seguinte questão: como garantir que uma cooperativa de crédito solidário seja uma alternativa real ao sistema bancário tradicional, mantendo-a fiel aos seus objetivos sociais e cumprindo as exigências legais às quais está submetida? Essa questão surgiu durante a fase de campo da pesquisa de mestrado intitulada "O cooperativismo de crédito solidário e as representações sociais da cooperação nos municípios de Araponga e Tombos-MG", mais especificamente durante as observações realizadas em reuniões junto à diretoria de uma das cooperativas estudadas (a Cooperativa de Crédito da Agricultura Familiar e Economia Solidária da Zona da Mata e Leste de Minas Gerais - Ecosol ZM e Leste de Minas Gerais) e a partir de entrevistas dirigidas aleatoriamente a cooperados. Tal pesquisa teve como base de estudo duas cooperativas de crédito solidário, vinculadas ao Sistema de Cooperativas de Crédito da Agricultura Familiar e Economia Solidária Sistema Ecosol, localizadas na Zona da Mata do estado de Minas Gerais.

A pesquisa de campo foi baseada em entrevistas semiestruturadas com 32 associados, 1 técnico agrícola que presta serviços a um dos postos de atendimento ao cooperado, o contador da Base Minas; diários de campo e observação, esta última, sobretudo em reuniões e cursos realizados no período em que eram feitas as entrevistas.

O tema que será debatido neste trabalho se mostrou recorrente nas discussões entre os dirigentes dessa cooperativa durante as reuniões, e também em conversas informais entre cooperados e pesquisadora. Há uma profunda preocupação em manter os objetivos sociais da cooperativa em primeiro lugarprevistos em estatuto e que serviram de base para a sua constituição -, mas também existe a preocupação em tornar seu funcionamento e sua gestão cada vez mais eficientes, mantendo assim a saúde financeira da cooperativa, uma vez que o aumento de seu quadro social vem acompanhado de um crescente aumento no risco de crédito, notadamente a inadimplência.

A discussão que segue está estruturada em subitens que apresentam, primeiramente, um panorama do surgimento do cooperativismo de crédito solidário e do Sistema Ecosol em Minas Gerais; a seguir, uma breve caracterização de Tombos, o município onde está a EcosolZM e Leste de Minas Gerais e, finalmente,

${ }^{1}$ Órgão superior de fiscalização e controle de todas as instituições financeiras em funcionamento no país. 
os discursos ${ }^{2}$ em torno da questão proposta.

\section{O cooperativismo de crédito solidário e o surgimento do sistema Ecosol em Minas Gerais}

As cooperativas de crédito solidário, no Brasil, surgiram como uma alternativa para as populações de baixa renda, sobretudo no meio rural. A ideia inicial era ter uma instituição financeira capaz de atender aos interesses dos agricultores familiares, que muitas vezes não possuem garantias patrimoniais como contrapartida para o acesso aos serviços através das instituições financeiras tradicionais. Como salienta ABRAMOVAY (2004:27), "os bancos são fortemente estimulados a conceder empréstimos sobre a base de garantias reais - e, portanto, a um público socialmente limitado". Tais fatos estimularam aqueles excluídos do público almejado pelos bancos comerciais a buscarem alternativas compatíveis com a sua realidade para suprir suas necessidades de serviços financeiros.

De acordo com Abramovay (2004: 21), na concepção do sistema bancário formal não havia, por parte da população pobre, demanda por serviços financeiros, pois estes "mal conseguem preencher as necessidades básicas de sua sobrevivência". Por isso, a possibilidade de serem pensados serviços compatíveis com o perfil dessa população era também suprimida. Bittencourt (2001) complementa, argumentando que, na visão dos grandes bancos comerciais, esse nicho da população não conseguia atender ao valor mínimo de capital para realizar transações financeiras.

Embora excluída do sistema bancário formal, essa população nunca esteve totalmente desprovida de mecanismos através dos quais pudesse suprir suas necessidades financeiras. Abramovay (2004) identificou entre algumas comunidades carentes laços de reciprocidade que facilitavam guardar dinheiro com pessoas mais conhecidas, como comerciantes. Esses recursos são disponibilizados pelo comerciante para demais pessoas da comunidade e garantem a ele um capital de giro maior. Essas "finanças informais" (ABRAMOVAY, 2004), apesar de operar sobre uma base social que permeia as relações familiares e de amizade, se processam baseadas em recursos reduzidos que não dão origem a investimentos.

Pensando nesses entraves e na necessidade de ter uma organização que facilitasse o acesso aos serviços financeiros básicos, atendendo às especificidades de um determinado público, foi que surgiram as primeiras iniciativas de cooperativas de crédito rural solidário no país. As primeiras cooperativas integram atualmente o Sistema de Cooperativas de Crédito Rural com Interação Solidária - Sistema Cresol, comatuação nos Estados do Sul do país ${ }^{3}$. Tendo o Cresol como inspiração, novas iniciativas surgiram na tentativa de se adequar aos seus contextos de origem.

É nessa perspectiva que surgem também as primeiras iniciativas que deram origem ao Sistema Ecosol. De acordo com Búrigo (2006), o Ecosol

\footnotetext{
${ }^{2}$ Para Alexander (1987), o discurso se refere "aos modos de argumentação que são mais consistentemente generalizados e especulativos que as discussões científicas normais". O autor diz que as discussões científicas normais costumam tratar de "peças específicas de evidências empíricas, de lógicas indutivas e dedutivas, de explicação através de leis gerais" e de métodos para verificar a autenticidade dessas leis gerais. O discurso, por sua vez, se propõe a ir além dos resultados da experiência imediata; "visa à persuasão pelo argumento mais que a predição", através da "coerência lógica, grau de abrangência, riqueza interpretativa, relevância valorativa, força teórica, beleza e textura do argumento". No caso deste artigo, a expressão "discurso" será utilizada no intuito de evidenciar a argumentação utilizada pelos cooperados da Ecosol ZM e Leste de Minas Gerais, no sentido de alcançar mais unidade e consistência para o trabalho coletivo empreendido.

${ }^{3}$ Em 2009, o Sistema Cresol, atualmente o mais consolidado entre os sistemas solidários, realizou um convênio de cooperação técnica com o Sistema Nacional de Cooperativas de Crédito da Agricultura Familiar - Creditag, através do qual esses sistemas se integraram, passando a constituir a Cresol Sudeste. O convênio chamou a atenção dos dirigentes das cooperativas Ecosol de Minas Gerais, em virtude da resolução dos problemas operacionais apresentados pelas cooperativas do Sistema Creditag, cujas características se assemelhavam aos seus problemas, levando a um mesmo convênio entre Ecosol e Cresol, em 2010.
} 
representa um esforço importante dos trabalhadores para reduzir a exclusão financeira e a pobreza e gerar mais equidade social. Traduz também uma manifestação econômica e política concreta de setores populares e sindicais que procuram, sob a ótica da economia solidária, construir cooperativas de crédito enquanto instrumentos que sejam capazes de enfrentar os desafios do setor financeiro e ampliar o mercado de crédito.

O surgimento do Sistema Ecosol no país está diretamente vinculado à articulação entre os Sindicatos dos Trabalhadores Rurais - STRs e a Central Única dos Trabalhadores - CUT, que já atuava em segmentos vinculados à economia solidária através da Agência de Desenvolvimento Solidário - ADS. Os trabalhos da ADS eram voltados para questões como crédito, reforma agrária e produção, porém, em determinado momento, os trabalhos relacionados com a questão do crédito passaram a abranger um público diferenciado e precisavam ser tratados de outra forma.

A partir dessa constatação, começam a realizar trabalhos e diagnósticos com vistas a criar um sistema financeiro solidário, surgindo em 2002, a Ecosol Central com sede em São Paulo-SP - juntando as três maiores cooperativas de crédito solidário existentes à época.

A ADS passa, então, a realizar cursos sobre cooperativismo em algumas regiões do país e a realizar diagnósticos locais em municípios onde já existiam trabalhos coletivos e mobilizações em torno de organizações de agricultores familiares, propondo a constituição de cooperativas de crédito nestes municípios.

Em Minas Gerais, os municípios escolhidos para acolher esses diagnósticos foram Araponga e Espera Feliz, em virtude do trabalho coletivo já realizado pela população rural e pela mobilização dos STRs. Porém, em virtude da existência de um posto de atendimento do Sistema de Cooperativas de Crédito do Brasil Sicoob em Espera Feliz, surge um impasse para a liberação da constituição de uma cooperativa. Assim, como alguns agricultores familiares de Tombos já estavam participando do processo de mobilização e, em virtude de sua proximidade geográfica com Espera Feliz, e da forte articulação das organizações locais, o projeto de constituição da cooperativa é transferido para Tombos.

Foram, assim, constituídas duas cooperativas singulares em Minas Gerais: nos municípios de Araponga e Tombos. O processo de constituição, no que diz respeito aos cursos de capacitação para os futuros associados, foi realizado de forma conjunta entre 2001 e 2002; a autorização formal de funcionamento pelo Banco Central aconteceu somente em 2003, e as cooperativas vieram iniciar o atendimento no princípio de $2005^{4}$.

\section{Tombos: Sede da Ecosol Zona da Mata e Leste de Minas Gerais}

No que diz respeito a Tombos, é um município mineiro que se situa na microrregião de Muriaé, a 389 km da capital Belo Horizonte, na divisa dos Estados de Minas Gerais e Rio de Janeiro, numa área de 283 $\mathrm{km}^{2}$, com densidade demográfica de $41 \mathrm{hab} / \mathrm{km}^{2}$, segundo dados do Ministério das Cidades (2009).

De acordo com dados do Instituto Brasileiro de Geografia e Estatística - IBGE, a população de Tombos somava, na contagem de 2007, 9.194 habitantes. Nas últimas décadas, a tendência em Tombos foi de aumento da população urbana em relação à população rural, o que, de acordo com Durán (2001), pode ter dois motivos: as políticas extensionistas de saúde e o controle da natalidade da década de 1970 podem ter causado influência sobre a taxa de natalidade da população, ou o aumento da pobreza no meio rural

\footnotetext{
${ }^{4}$ De acordo com as normas vigentes na época, as cooperativas de crédito deveriam primeiro reunir o número de associados e o capital social exigido pelo Bacen para solicitar a autorização de funcionamento. Após a aprovação deste para o funcionamento fariam, então, um plano de viabilidade, que por sua vez também deveria ser encaminhado a este órgão e, só após sua aprovação, poderiam finalmente abrir suas portas e realizar seus trabalhos.
} 
pode ter levado os agricultores a procurarem melhores condições de vida no meio urbano ${ }^{5}$.

Os agricultores familiares em Tombos, desde a década de 1990, sempre tiveram um papel ativo na vida política do município. Por isso, durante um bom tempo houve uma polarização política que separava os agricultores vinculados ao STR e os grandes proprietários de terra.

Em se tratando de empreendimentos coletivos, no município de Tombos os agricultores familiares possuem um histórico que vem desde a constituição do STR e, a partir da articulação em torno deste, outras organizações foram sendo criadas. Em 1998, foi criada a Associação de Pequenos Agricultores e Trabalhadores Rurais - Apat, cuja missão é possibilitar a viabilização de processos de organização e comercialização da produção local (SANTOS, FLORISBELO, 2004). Também em 1998 um grupo de mulheres começou a se organizar e deu origem, em 2000, à Associação de Mulheres Trabalhadoras Rurais de Tombos - Amart. Justamente em virtude dessa forte articulação em torno da organização dos agricultores que foi possível realizar em Tombos a mobilização inicial para a constituição da Ecosol ZM e Leste de Minas Gerais.

No que diz respeito ao seu surgimento, seu quadro social de constituição era formado por 29 pessoas físicas e 3 jurídicas, inicialmente com área de atuação restrita ao município. Após dois anos, como não havia meios de se concretizar a abertura de outra cooperativa em Espera Feliz, que já tinha um grupo formado para tal, foi decidido então enviar ao Bacen a proposta de constituição de Postos de Atendimento Cooperativo - PACs, vinculados à sede de Tombos. Assim, em 2007, foram inaugurados os PACs nos municípios de Espera Feliz e Simonésia. Atualmente, a cooperativa possui 845 cooperados, divididos entre a sede no município de Tombos e três PACs, um no distrito
Catuné, em Tombos e os outros dois nos municípios acima citados.

De acordo com os princípios que regem a atuação do Sistema Ecosol e com os seus objetivos sociais previstos em estatuto, a proposta dessa cooperativa é atuar junto aos agricultores familiares dos municípios já citados, de forma a garantir que estes consigam ter recursos financeiros suficientes para que possam investir em suas propriedades e produções sem recorrer aos bancos comerciais locais e, com isso, correrem o risco de não serem atendidos satisfatoriamente.

A atuação da Ecosol ZM e Leste de Minas Gerais, evidenciada nos dados da pesquisa, é baseada em valores de parentesco e reciprocidade e está diretamente pautada por ações que visam manter esses princípios norteadores, como poderá ser visto mais adiante. Quando surgiu a ideia da cooperativa, através de uma mobilização dos agricultores vinculados ao STR e associações, o discurso era voltado a constituir uma organização que atendesse aos "interesses bancários" dos trabalhadores rurais da região, de uma forma específica, mantendo as características intrínsecas ao grupo que eram, de certa maneira, desrespeitadas pelos bancos comerciais, cujo atendimento visava apenas a sua própria manutenção financeira.

Assim, a cooperativa tem como objetivos sociais, de acordo como seu estatuto:

I - Propiciar, através da mutualidade, assistência financeira e técnica aos associados, em suas necessidades pessoais e atividades específicas, com a finalidade de: melhoria de condições de vida sua e da família, fomentando a produtividade e a produção rural, bem como a sua industrialização e comercialização;

II - A formação educacional de seus associados, no sentido de fomentar o cooperativismo e associativismo, através da ajuda mútua, da

\footnotetext{
${ }^{5}$ Importante ressaltar que mesmo morando na cidade, no núcleo urbano do município, os moradores de Tombos não perderam o vínculo com o meio rural, muitos mantém um pequeno sítio e continuam produzindo; outros ainda têm vínculos através de parentes próximos, como pais e avós.
} 
economia sistemática e solidária do uso adequado do crédito;

III - Propiciar a formação educacional a seus associados, com base na agroecologia e na preservação do meio ambiente e resgatar a importância da produção orgânica e dos produtos naturais. (TOMBOS, 2007, artigo 2. ${ }^{\circ}$ )

Tais objetivos sociais pretendem garantir que os princípios norteadores do Sistema Ecosol como um todo sejam efetivamente realizados no dia a dia dessa cooperativa especificamente. Esses princípios se baseiam em garantir que as cooperativas operem através de uma gestão democrática e participativa e de um trabalho administrativo transparente, descentralizado e em cooperação com o grupo maior de associados, que se adapte às condições dos municípios onde está inserida a cooperativa e seus postos de atendimento, "a fim de estabelecer um sistema eficaz de controle social e de valorização da comunidade". Duas formas muito características da concretização desses princípios e objetivos sociais em ações aparecem na liberação de empréstimos e na admissão de novos cooperados, por exemplo. As relações de cunho pessoal e subjetivas permeiam aquelas que seriam meramente econômicas, se fossem feitas por meio de outras instituições financeiras, uma vez que, para aceitar um novo membro no grupo de cooperados, ou mesmo liberar a realização de um empréstimo, a diretoria se reúne e discute entre si quem conhece o pleiteante, quais são seus laços de parentesco, como essa pessoa se comporta dentro da comunidade, onde mora e o grau de confiança que inspira para aqueles que a conhecem.

Nessa perspectiva, para os associados de uma cooperativa constituída nos moldes acima citados:

O crédito exprime (...) um ativo, um meio do qual dispõe a família na obtenção do que necessita para reproduzir-se. São relações estáveis, previsíveis e que se inserem dentro de um horizonte social relativamente conhecido pelos atores. (ABRAMOVAY, 2004: 45)
Por isso mesmo é que o elemento confiança, inserido nas relações entre cooperativa e cooperados, é de suma importância e toma lugar de destaque para aqueles que constituem o quadro social da Ecosol ZM e Leste de Minas Gerais, cuja relevância recai também sobre o grau de conhecimento e o próprio compartilhamento de uma história de vida pelos agricultores e assegura a manutenção dessas relações e consequente operacionalização da cooperativa. Assim como salienta Búrigo (2006: 54): "(...) o crédito não deve ser visto como um fim em si mesmo. Ele é um meio, é um instrumento que pode e deve promover desenvolvimento". Eé exatamente com esse propósito que a Cooperativa de Crédito Rural da Agricultura Familiar e Economia Solidária da Zona da Mata e Leste de Minas Gerais se propõe a atuar em sua área de abrangência.

Diante das especificidades descritas, a Ecosol ZM e Leste de Minas Gerais, representada por seus cooperados, se vê diante de um impasse: continuar atuando como uma cooperativa de crédito solidário ou partir para uma forma mais tradicional de instituição financeira?

\section{A QUeStão da InSTITUCIONALIZAÇÃo: SER OU NÃo SER?}

$\mathrm{O}$ que caracteriza uma cooperativa de crédito solidário como uma instituição financeira alternativa aos bancos comerciais? É cabível manter o título de "alternativa" frente ao que é possível realizar na prática e àquilo que seus cooperados idealizam para seu funcionamento? Diante dessas questões e após a observação de uma reunião de diretoria e algumas entrevistas na Ecosol ZM e Leste de Minas Gerais, o dilema será apresentado, neste texto, em três perspectivas que emergem nos discursos e que aparecerão nos próximos itens, como: a) o discurso a favor das normas, cujo argumento central está focado na atuação da cooperativa o mais próximo possível de um banco comercial; b) o discurso a favor do objetivo social, interessado na diferenciação institucional que uma cooperativa de crédito solidário é capaz de proporcionar aos seus cooperados; e, por fim, c) o dilema em si, o "ser ou não ser", que permeia também 
os discursos anteriores.

É preciso salientar que essas perspectivas foram separadas para fins analíticos com o objetivo de evidenciar os discursos; entretanto, na prática, no dia a dia da cooperativa e de seus cooperados, perpassamse constantemente e estão sempre misturadas, de uma forma que raramente é possível diferenciá-las.

\section{a) Somos uma instituição financeira: o discurso a favor das normas}

A operacionalização da Ecosol ZM e Leste de Minas Gerais, em grande parte, está vinculada ao horário dos bancos comerciais, uma vez que a cooperativa necessita depositar todo o recurso que circula em seu caixa durante o dia, pois não possui cofres adequados para grandes somas. Esse e alguns outros detalhes em seu funcionamento - como a questão do sigilo bancário, por exemplo - guardam marcantes semelhanças com a operacionalização dos bancos comerciais e, em alguns momentos, confundem-se no discurso de seus cooperados, mostrando uma tendência a comparação dos serviços prestados por essas instituições financeiras.

Os discursos evidenciam que, embora a cooperativa tenha uma base de atuação totalmente diferente dos bancos, priorizando suprir as necessidades dos agricultores familiares que estão excluídos do rol de serviços financeiros das outras instituições, há uma preocupação em ter tanto um sistema de controles internos quanto rigor no cumprimento de certas normas bastante semelhantes aos encontrados nas instituições tradicionais.

Como salienta Búrigo (2003), essa postura frente à atuação da cooperativa defende a prestação de serviços estritamente financeiros e, dessa forma, uma atuação com maior eficácia do que o sistema bancário tradicional. No caso específico da Ecosol ZM e Leste de Minas Gerais, isso é evidenciado nos discursos que defendem que os funcionários da cooperativa e coordenadores que nela atuam no dia a dia precisam ter em mente que estão lidando com uma instituição financeira, fato que acarreta um grau de responsabilidade ainda maior para eles, pois administram diretamente o dinheiro de agricultores familiares, como eles próprios e, na maioria dos casos, agricultores que compõem o mesmo círculo de parentesco e amizade.

(...) falá pro povo, ó, se cê chegá depois das três, seje meu amigo, seja o que for, tá fechado, tá fechado! (Técnico Base Minas, Tombos, 2009)

Isso é reforçado nas falas que seguem, justamente comparando-a com o funcionamento dos bancos comerciais, ressaltando a questão da segurança, transparência e confiabilidade que a cooperativa via funcionários e coordenadores - precisa passar para os seus cooperados atuais e para aqueles que pretendem atingir com sua prestação de serviço. Esses discursos mostram que, embora seja uma instituição gerida por agricultores e funcione de uma forma mais simples e menos burocrática que os bancos comerciais, ela ainda precisa seguir alguns procedimentos imprescindíveis para sua plena operacionalização:

(...) e cada vez mais, gente, o pessoal tá acreditando mais e tá vendo que tipo de coisa é essa aí e vai tá depositando mais e aí é que aumenta mais a responsabilidade... então tem que tomá bastante cuidado, o caixa principalmente que convive o dia a dia ali, sabe assim mostrá, quanto mais responsabilidade e o jeito do atendimento, se você chega lá, o camarada vê que todo mundo tem acesso e entra e sai, o cara não de-po-si-ta! Olha eu te falo, tem gente que já foi na cooperativa, eu sei disso, se ele vê, ele fica com medo de depositá, as vez cê tinha dez mil pra depositá, deposita só no banco. "eu depositá dinheiro ali? Eu vejo todo mundo entrando e saindo ali! Vai sabê que que o meu dinheiro... sei lá!" Agora se você chega e o negócio é organizado... Por que que cê deposita no Banco do Brasil? Cê chega lá cê consegue entrá dentro do caixa? Cê consegue chegá lá e passá pra lá e pra cá?

(...) Então a gente tem que mostrá serviço pros 
outros tamém essa responsabilidade, porque senão não cria a transparência de que o negócio é seguro, né?" (Técnico Base Minas, Tombos, 2009)

cê vai no Banco do Brasil e no Itaú pra vê, nós não panha o talão de cheque lá no Itaú se não tivé a assinatura, se não tivé presente eu e o Toninho. Num panha o talão, não é dinheiro emprestado, não! É um talão de cheque... (Coordenador, Tombos, 2009)

Essas questões passam a ser cada vez mais discutidas, sobretudo em virtude do aumento do número de cooperados, e consequente aumento da movimentação financeira da cooperativa, fatores que preocupam os coordenadores uma vez que levam a perda dos laços de proximidade entre os membros do quadro social, que sempre foram considerados como um diferencial dessa cooperativa.

Embora exista a defesa de uma maior padronização dos procedimentos realizados pela cooperativa na prestação de serviços aos seus cooperados, seguindo os moldes do atendimento dos bancos comerciais, há também a preocupação de realizá-los sempre de acordo com a proposta de um empreendimento solidário, com a flexibilidade que um empreendimento desses pressupõe, como pode ser percebido na fala abaixo:

(...) tem algumas coisas que cê tem que ser flexível, mas dentro das norma e resolução, viu? Não tem como cê sê intermediário nesse ponto aí, se é pra fulano eu vô faze dessa forma, se é pra bertano eu vô fazê dessa outra forma, né? Não tem como... (Coordenador 1, Tombos, 2009)

Porém, nesse mesmo trecho citado, é possível perceber a preocupação com a uniformidade no tratamento dispensado aos cooperados e certa tendência à padronização de procedimentos, com vistas ao cumprimento das normas e resoluções que são baixadas tanto pelo Bacen quanto as que são deliberadas no âmbito interno da cooperativa para seu melhor funcionamento.

\section{b) Somos uma cooperativa solidária, não um banco: o discurso a favor do objetivo social}

A Ecosol ZMe Leste de Minas Gerais, na visão de seus cooperados, têm uma forma de atuação perante seus associados que a diferencia substancialmente dos bancos comerciais que atuam no município de Tombos.

Assim, a constituição da cooperativa veio para tentar atender aos agricultores familiares do município, através da prestação de serviços bancários para aqueles que habitualmente não o conseguiam pelas vias convencionais, como denota a fala a seguir:

Daí é o objetivo que a gente criou foi a questão de buscar um crédito solidário de agricultor para agricultor, e sair daquela dificuldade que os agricultores têm de negociar com um banco, com o gerente de um banco que tá lá de gravata, é... muitas se atrapalham até na hora de entrar num banco ou na hora que entra numa porta giratória. (Associada Ecosol, Tombos, 2009)

cê chega no banco pro cê fazer um empréstimo, alguma coisa assim, cê tem que fazer o projeto, a documentação tem que tá tudo em dia, num sei o que, tal pra lá. E na cooperativa é diferente, é o companheiro que conhece o companheiro, que tem minimamente burocracia, certo? (Associado Ecosol, Tombos, 2009)

As opiniões apresentadas pelos entrevistados se apoiam em um discurso a favor da operacionalização da cooperativa de uma maneira significativamente diferente daquela empreendida pelo sistema financeiro tradicional. Nessa perspectiva, a visão que os cooperados - agricultores familiares - têm do atendimento perpassa valores tais como: a confiança; o vínculo que mantêm entre si, o companheirismo e a burocracia mínima necessária para o acesso aos serviços financeiros de que necessitam. Fatores que marcam a forma de atuação da Ecosol ZM e Leste de Minas Gerais. 
Como nos mostra Bittencourt (2001), os bancos comerciais possuem um "alto custo operacional" e "excessiva burocracia", que os levam a ter preferência em conceder empréstimos e financiamentos aos agricultores que possam lhes oferecer os menores riscos "para a aplicação e para o retorno [desses] recursos". Esse fato tem por consequência a exclusão dos agricultores menos capitalizados de seu público preferencial, fazendo com que a cooperativa tenha como uma de suas funções principais suprir essa lacuna. Diferente das limitações viabilizadoras traçadas pela cooperativa, as regras dos bancos comerciais são vistas como constrangimentos para os associados daquela e, a partir disso, a visão que têm dos serviços prestados pela cooperativa está diretamente ligada ao fato de estarem lidando com pessoas do meio rural também, tanto os que utilizam quanto os que estão na parte operacional, o que dá origem a um discurso já institucionalizado, como pode ser observado a seguir:

a Ecosol, igual eu te falei, ela é diferente, né, ela tem um trabalho sério e ali ela só vai dar errado se os sócios que entrarem ali, né, quisé sacanear, quisé assim não levar as coisa muito a sério. Por exemplo, se vêm uma inadimplência muito grande, os outros sócio, né, que é um sistema solidário, vão sofrer com isso né. (Associado Ecosol, Tombos, 2009)

Contrária à relação que os agricultores cooperados entendem ter com os bancos comerciais, uma vez que não existe entre estes últimos uma preocupação em atender a demandas específicas de uma parte de seus usuários, sobretudo os menos capitalizados, também não existe uma preocupação, por parte dos clientes destes - e nem cabe haver -, em garantir a viabilidade financeira da instituição, pois esta se dá por outros meios, alheios à sua responsabilidade, como, por exemplo, através de investimentos em projetos ou empresas de lugares distintos. Assim, para uma cooperativa de crédito, é importante que esta tenha, de acordo com GRISA (2003: 61), "uma atuação local. Os agricultores devem ter um controle social sobre elas. Eles precisam sentir-se donos, como realmente são, donos daquela instituição", para que assim consigam garantir que seu funcionamento realmente alcançará as suas necessidades. Entretanto, esse papel do cooperado e, principalmente, todas as questões envolvidas em seu cumprimento, são tarefas árduas a uma cooperativa de crédito rural, formada por agricultores familiares. A fala proferida em uma reunião na Ecosol ZM e Leste de Minas Gerais demonstra o quão difícil é coordenar algumas destas questões em prol do entendimento das reais necessidades da cooperativa. Por exemplo, o crescimento necessário para se manter no sistema de crédito e as dificuldades em realizar a capacitação dos cooperados devido ao seu maior número:

(...) No papel de coordenador, de representante executivo dela lá no dia a dia é tê um pouco desse jogo de cintura, as vez você tem que dar dois passo atrás pra dá três pra frente, né? Mas sempre tê bem claro as linhas de raciocínio da cooperativa, as diretrize dela, a missão dela digamos assim, né, pra não fugi desse contexto, senão fica sem respaldo aquilo que foi deliberado pelo conselho de administração, assembléia e assim por diante... (Coordenador 1, Tombos, 2009)

Isso também demonstra uma preocupação com a responsabilidade dos diretores perante as decisões que são tomadas em reunião e a forma como repassam isso aos cooperados que procuram a Ecosol. Uma vez que algumas medidas - como limite do valor dos empréstimos - são necessárias para a saúde financeira do sistema como um todo, principalmente entre as cooperativas do Estado, mas nem sempre são bem entendidas pelos cooperados, que pensam no benefício imediato que lhes foi prometido no ato da associação, ou seja, acesso rápido e fácil a serviços financeiros. Demonstra também a falta de conscientização entre o grupo de associados e a mudança de mentalidade que deve ser promovida entre estes - já que entre os coordenadores isso está bem consolidado -, de que é necessário investir na cooperativa, fazendo poupança 
e aplicação para que esta tenha recursos suficientes para continuar prestando os serviços de financiamento.

\section{c) Instituição financeira tradicional versus Cooperativa solidária: ser ou não ser?}

A ideia de crescimento e fortalecimento das cooperativas de crédito, difundida pelo Banco Central, se difere, em partes, dos objetivos pretendidos pelas cooperativas de crédito solidário. De acordo com Tombini (2008), para que as cooperativas de crédito possam se fortalecer, é preciso que aumentem a sua participação no SFN. Para ele, que é um representante do Bacen, isso seria possível através das diretrizes da sustentabilidade, transparência e responsabilidade social. Vistas dessa maneira, pode-se acreditar que não existam conflitos inerentes aos discursos dessas instituições; porém, quando examinadas as concepções presentes em cada uma dessas diretrizes, de acordo com o Banco Central, num primeiro momento, percebe-se que há uma forma diferenciada de pensamento. Para o Bacen, na ideia de sustentabilidade para as cooperativas de crédito está a verticalização do sistema, ou seja, as cooperativas devem se fundir e as menores serem incorporadas pelas maiores, algo totalmente fora de questão para o cooperativismo de crédito solidário que trabalha na lógica de fortalecimento da organização local.

Essas diferenças entre as concepções institucionais sobre a viabilidade de uma cooperativa de crédito, no que tange à Ecosol ZM e Leste de Minas Gerais, começam a se refletir nos discursos dos cooperados, não exatamente sob a forma apresentada anteriormente, mas, sobretudo, através da comparação entre a operacionalização da cooperativa e os bancos comerciais, com os quais alguns cooperados precisavam transacionar. Isso pode ser observado num pequeno fragmento de uma discussão na reunião do conselho de administração, em maio de 2009:

Eu não sô contra a regra, não. (...) A gente passa uma raiva com esses banco, cê chega na porta é um minutinho pras três, cê chegô, o relógio deles já deu três hora, aí não adianta, cê pode tá com dinheiro pra depositá, que eles não... aquilo dá muita raiva! (Associada Ecosol, Tombos, 2009)

agora cê imagina se todo dia eles atenderem depois das três, ninguém ia duas e meia, ninguém ia antes das três, só ia depois das três. (Coordenador 3, Tombos, 2009)

eu não sei, é porque nosso sistema, eu assim pra mim, desde que eu entrei no sistema ecosol, o sistema ecosol era diferente, era um diferenciado porque as pessoa vem da roça, né, daí aquele jeitinho, né? (Associada Ecosol, Tombos, 2009)

"mas aí se cê fô dando jeitinho..." (Coordenador 2, Tombos, 2009)

"Tem que tê regra! Porque se você abri exceção pra um dia atendê um depois das três, aí ele já divulga: "cê pode ir lá depois das três que eles te atende" e vai divulgando, daqui uns dia cê não consegue fechá..." (Técnico Base Minas, Tombos, 2009)

Nesse sentido, embora conscientes de que estão gerindo uma cooperativa de crédito e de que esta é um instrumento para o alcance dos serviços financeiros que necessitam de uma maneira "personalizada", pois é gerida pelos próprios agricultores e procura moldar os serviços prestados para as necessidades destes, surge nas discussões uma preocupação latente com a forma de atuação desta em virtude do crescimento de seu quadro social. E essa preocupação se reflete no discurso dos diretores sob a comparação do funcionamento da Ecosol ZM e Leste de Minas Gerais com os bancos da região.

Mesmo com todo o entendimento que têm sobre cooperativismo - a cooperativa é de sua responsabilidade -, ainda assim os cooperados se confundem quando precisam definir a cooperativa, como sendo um banco ou uma outra coisa que eles não conseguem definir. Acham que a cooperativa de crédito é um banco, o banco dos agricultores, e surpreendem- 
se com tudo que são capazes de fazer administrando-a.

Os agricultores viram que, quando a gente traz uma pessoa pra Ecosol, a gente fala que a cooperativa não é minha, não é porque eu tô lá na coordenação ela é minha, cada sócio é dono, a gente fala isso pra eles. Então, eles sentiram que, eles tão aprendendo a administrar um banco! E isso a maioria dos agricultores achava que isso nunca podia existir, que um agricultor poderia tomar conta de um banco! Não podia ser administrador de um banco. (Associada Ecosol, Tombos, 2009)

Embora os agricultores tenham que adquirir inúmeros conhecimentos sobre o funcionamento de uma instituição financeira para gerir uma cooperativa de crédito, percebe-se que as normas que a regem dão subsídio para que estes possam realizar seus objetivos de captação de recursos e melhoria de renda e bem-estar das famílias e comunidades, inerentes à maior autonomia de gestão administrativa que essas cooperativas possuem e as diferencia de outras modalidades de instituições financeiras (BITTENCOURT, 2001).

\section{Considerações Finais}

Se, por um lado, a cooperativa precisa crescer, já que há a necessidade de atender às exigências formais do SFN, por outro, emerge o conflito de não querer se desprender de seus valores e objetivos sociais. Assim, duas questões parecem pertinentes: em que momento uma cooperativa de crédito solidário percebe que sua forma de atuação precisa mudar? E até que ponto essa mudança a coloca num "conflito de identidade"?

No caso da cooperativa em questão, isso aconteceu em virtude do aumento do número de associados e da sua incapacidade em atendê-los satisfatoriamente. É uma discussão que deixa os diretores e os responsáveis pela operacionalização do sistema impacientes, mas que, embora seja urgente, ainda não pode ser suficientemente respondida. Alguns apontam para uma maior burocratização dos processos empreendidos pela cooperativa, defendem que deve haver mais responsabilidade e preocupação por parte daqueles que cuidam da operacionalização da cooperativa. Porém, nesse caso, onde ficam os objetivos sociais, a proposta de um empreendimento alternativo, solidário e com a pretensão de atingir aqueles cujos interesses econômicos estão à parte do rol do público almejado pelos bancos comerciais?

Não há uma saída definitiva, tampouco imediata, para esse dilema. Existem apenas alguns apontamentos, alguns sinais que podem (devem?) ser seguidos, mas que ainda não garantem que os resultados contemplarão todos os aspectos considerados importantes.

As diferentes formas de apreensão do ambiente externo e de responder a ele, através de tentativas de consolidação de instituições estão presentes nas falas dos atores imbuídos em consolidar essa nova forma de atuação do crédito, conforme os estímulos que vêm recebendo. Os associados, e em especial os membros da diretoria da Ecosol, são os agentes da mudança institucional que respondem dessa forma, após perceberem mudanças na estrutura de incentivos provocados por alterações nas preferências das pessoas. Essa mudança institucional está posicionada aqui como um dilema entre a relação das instituições, "constrangimentos humanamente percebidos que moldam a interação humana" (NORTH, 1990: 03), e uma organização, o Bacen.

É difícil concordar com a legislação, mas também é difícil apontar uma alternativa. Sem as normas seria como vários outros tipos de cooperativas, que não têm um órgão específico pra cuidar do seu "bom funcionamento", e acabam, na maioria das vezes, ficando à mercê de pessoas mal-intencionadas.

No caso de Tombos, os coordenadores são agricultores familiares ou pessoas que têmalgum vínculo direto com a agricultura. Também são pessoas muito politizadas e muito informadas sobre a legislação e os normativos para cooperativas de crédito. Isso faz com que saibam com qual realidade estão lidando e também que tenham alguma noção de quanta responsabilidade têm nas mãos. 
De acordo com alguns entrevistados, uma das possíveis soluções para que resolvam esse dilema é a capacitação dos cooperados, um trabalho de base forte, cujas ações consigam alcançar aqueles que vieram até a cooperativa, se associaram, mas não têm a menor noção do que ela significa e das responsabilidades que acarreta. Um entrave, porém, na consecução dessa solução está vinculado à falta de recursos financeiros da cooperativa que possam ser direcionados para realizar especificamente esse trabalho.

Assim, ainda não é possível apontar um caminho que solucione esse dilema. A classificação das cooperativas de crédito como instituição financeira abre um leque de opções para as cooperativas de crédito nem sempre boas opções - e, ao que parece, em Tombos, dá uma certa segurança aos coordenadores, pois, sendo "vigiadas de perto" pelo Banco Central, têm a garantia de que este é um empreendimento sério, duradouro e que não vai ficar nas mãos de qualquer um, uma vez que exige muita responsabilidade por parte daqueles que a representam legalmente.

\section{REFERÊNCIAS}

ABRAMOVAY, Ricardo. Adensa vida financeira das famílias pobres. In: . (Org.). Laços financeiros na luta contra a pobreza. São Paulo: Annablume/FAPESP, 2004.

ALEXANDER, J. C. O novo movimento teórico. Revista Brasileira de Ciências Sociais, Campinas, v.2, n.2, jun. 1987. p.05-28.

\section{BITTENCOURT, Gilson Alceu. Cooperativas de} crédito solidário: constituição e funcionamento. 2.ed. Brasília: NEAD, ADS/CUT, CNDRS, MDA, 2001.

BÚRIGO, Fábio Luiz. Cooperativas de crédito. In: PRETTO, José Miguel (org.). Cooperativismo de crédito e microcrédito rural. Porto Alegre: Editora da UFRGS. p.51-57, 2003.
Finanças e solidariedade: uma

análise do cooperativismo de crédito rural solidário no Brasil, 2006. 374 f. Tese (Doutorado em Sociologia Política). Centro de Filosofia e Ciências Humanas, Universidade Federal de Santa Catarina, Florianópolis, 2006.

DURÁN, Regis Francisco Mairena. A Participação de Atores Sociais na Formulação do Plano de Desenvolvimento Rural do município de Tombos-MG. 140 f. Dissertação (Mestrado em Extensão Rural). Departamento de Economia Rural, Universidade Federal de Viçosa, Viçosa/MG., 2001.

GRISA, Sady. O sistema Cresol. In: PRETTO, José Miguel (Org.). Cooperativismo de crédito e microcrédito rural. Porto Alegre: Editora da UFRGS, 2003.p. 59-64.

IBGE, Instituto Brasileiro de Geografia e Estatística. Cidades. Disponível em: < http://www.ibge.gov.br/ cidadesat/topwindow.htm?1>. Acesso em 08 maio 2008; 08 set. 2009.

MINISTÉRIO DAS CIDADES. Perfil Municipal. Disponível em: <http://geosnic.cidades.gov.br/src/ php/frmPerfilMunicipal.php?idIBGE=316920>. Acesso em 08 maio 2008.

NORTH, Douglass. Institutions, Institutional Change and Economic performance. Cambridge: Cambridge University Press, 1990.

SANTOS, Ailton Dias dos. FLORISBELO, Glauco Regis. Desarrollo territorial, cambio institucional y productividad: sistematización de tres experiencias en el Estado de Minas Gerais, Brasil. Viçosa (MG): CTA-ZM, 2004. Disponível em: http://www.grupochorlavi.org/desarrolloterritorial Acesso em dez/2007.

TOMBINI, Alexandre. Desafios para o crescimento 
do cooperativismo de crédito na visão do Banco Central do Brasil. In: SERVIÇO NACIONAL DE APRENDIZAGEM DO COOPERATIVISMO (SESCOOP). Conjuntura e perspectivas do cooperativismo de crédito. Coletânea de artigos. Brasília (Série Desenvolvimento em Cooperativa). p.23-28, 2008.

TOMBOS. Estatuto social Cooperativa de Crédito da Agricultura Familiar e Economia Solidária da Zona da Mata e Leste de Minas

Gerais, 2007. Aprovado em 25 de março de 2007.

RECEBIDO EM 14/12/2010

ACEITO EM 29/6/2011 